\title{
Logistik Dalam Beragam Perspektif; Evolusi Konsep, Praktik, dan Isu Kebijakan di Indonesia
}

\author{
Akhmad Yunani ${ }^{1}$,Dhanang Widijawan ${ }^{2}$ \\ ${ }^{1}$ Universitas Telkom \\ email: akhmadyunani@telkomuniversity.ac.id \\ Dhanang Widijawan \\ ${ }^{2}$ Politeknik Pos Indonesia dan Sekolah Tinggi Manajemen Logistik \\ email: dhan_poltekpos@yahoo.com
}

\begin{abstract}
Abstrak
Logistics in terms of both conceptually and practically always emerge. Logistics issues concern on how to distribute products efficiently in order to satisfy customer requirements. There are many entities involved in performing logistics activites in the supply chain system. This article discusses the evolution of logistics concept and relating issues. Recently, the convergence of logistics emerges along with the changes of technology and environment. Postal service is naturally doing logistics activities. The activities of postal service cover all the spectrum of logistics business; collecting, handling, warehousing, transporting, delivery, and customer relationship management. Therefore, the government declared that the postal is the backbone of national logistics. Unfortunately, the regulation governing the logistics industry is still confusing, particularly in distinguishing the postal and logistics itself. Indonesia's logistics vision and objectives can be realized when there are conducive laws and regulations, adequate infrastructure, the availability of skillful labors, information technology support, and a world class logistics service provider that will encourage the realization of the superior commodities that will boost the competitiveness of the nation.
\end{abstract}

Kata Kunci: daya saing negara, kinerja logistik, konvergensi logistik, logistik pos 


\section{PENDAHULUAN}

Banyak problem ekonomi berawal dari permasalahan logistik. Sebuah perusahaan pupuk mengalami kesulitan pasokan gas sehingga terancam kelangsungan produksinya, dan tentu saja konsekuensi ekonomis yang lebih besar mengancam di kemudian hari. Harga semen di beberapa wilayah Timur Indonesia mencapai sepuluh kali lipat lebih dibandingkan harga di wilayah Jawa. Kesulitan distribusi logistik pemilu berpotensi mengancam kelancaran pelaksanaan pemilu. Sebuah perusahaan dapat unggul atau ditinggal pelanggan karena permasalahan logistik. Permasalahan logistik juga memegang peran sentral dalam pembentukan daya saing nasional suatu bangsa.

Logistik juga merupakan salah satu sumber keunggulan bersaing yang signifikan bagi suatu perusahaan (Mentzer 2004). Salah satu rumusan strategi yang baik dalam bersaing menurut Porter adalah kemampuan perusahaan untuk "menyelaraskan" rantai nilai tersebut sesuai dengan dinamika perubahan kebutuhan konsumen. Kala lingkungan bisnis berubah sedemikian cepat akibat kemajuan teknologi dan pengaruh global, tuntutan konsumen terhadap produk yang berkualitas dan andal, kecepatan tanggapan perusahaan, dan keandalan produk semakin

\section{METODE PENELITIAN}

Penelitian menggunakan pendekatan kualitatif melalui studi literatur dari berbagai dokumen dan sumber yang relevan untuk memetakan kondisi dan perkembangan logistik di Indonesia.

\subsection{Evolusi Konsep Logistik}

Pemikiran tentang logistik berkembang dari perspektif yang fokus pada aktivitas transportasi dalam ekonomi pertanian sampai pada pandangan bahwa logistik dapat menjadi salah satu pembeda dan komponen kunci dalam strategi bisnis, diferensiasi, dan link kepada pelanggan. Pemahaman logistik itu sendiri mengalami evolusi seiring dengan perkembangan lingkungan, dari mulai pengertian distribusi fisik yang menekankan pada biaya dan faktorfaktor yang mempengaruhi distribusi produk pertanian, sampai pemahaman bahwa logistik sebagai sebuah sistem mulai perencanaan sampai implementasi dan kontrol terhadap efisiensi dan efektivitas aliran dan penyimpanan barang, jasa, dan informasi terkait dari titik asal sampai titik konsumsi untuk memenuhi kebutuhan pelanggan. Kent dan Flint (1997) merumuskan model kronologi pemikiran tentang logistik sebagai berikut:

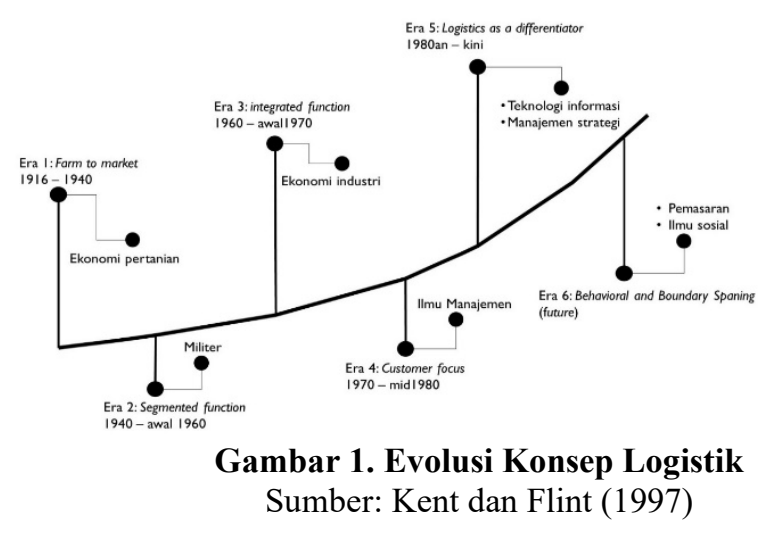

2.2. Model Rantai Pasok

Untuk menjamin keandalan pasokan material, Ford harus berinvestasi di tambang batubara, bijih besi, hutan, pabrik kaca, dan bahkan lahan untuk menanam kedelai sebagai bahan baku pabrik cat. Komitmen Ford untuk pemenuhan material mandiri mendorongnya untuk membeli hampir 1,2 juta hektar tanah di Brazil untuk menanam karet yang disebutnya Fordlandia. Ford ingin mengendalikan pasokan material dan komponen.Untuk mengangkut material ke sungai Rouge dan produk jadi ke dealer, Ford juga berinvestasi di kereta api, truk, dan juga kapal. Ini semua dilakukan untuk mengendalikan seluruh aspek persediaan untuk lebih dari 40 jaringan pabrik, servis, dan perakitan yang tersebar di seluruh U.S.A., Kanada, Australia, New Zealand, U.K. dan Afrika Selatan ke dealer di seluruh dunia. Ford merupakan contoh pebisnis yang paling ambisius dalam soal integrasi vertikal, dan ia menyadari perlunya bantuan. Pada puncaknya, integrasi vertikal ini menghadapi berbagai hambatan ekonomis, regulasi, dan serikat pekerja yang menuntut produk dan jasa pendukung harus dipasok oleh pemasok independen. Berikutnya, fakta menunjukkan bahwa pemasaran yang efektif ternyata terbangun melalui jaringan yang kuat dengan dealer independen. Disamping itu, Ford juga menemukan bahwa perusahaan yang fokus dapat bekerja secara lebih efisien. Ford akhirnya beralih strategi dari kendali berbasis kepemilikan menjadi kendali berbasis hubungan hubungan yang serasi antar penyalur. Sumber daya finansialpun dapat difokuskan pada pengembangan dan pemeliharaan kompetensi inti. Pada akhirnya, Ford berkesimpulan bahwa tidak ada satu perusahaanpun yang dapat mencukupi diri sendiri (Bowersox dan Closs, 1996). Model rantai pasok menghubungkan titik-titik proses yang terbangun dan melibatkan berbagai entitas bisnis (pemasok, pabrikan, distributor, retailer, dan pelanggan) untuk me-match-kan antara supply dan demand sehingga tercipta nilai tambah bagi pelanggan dan profit bagi perusahaan. Secara sederhana, rantai pasok tersebut dapat digambarkan sebagai berikut: 


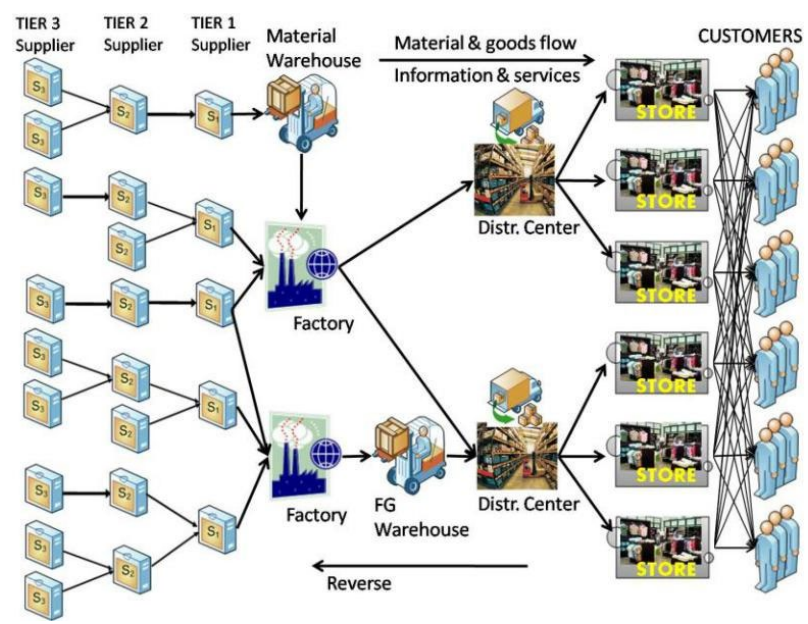

Gambar 2. Model Tipikal Rantai Pasok Dalam Manufaktur

Gambar tersebut menunjukkan bahwa banyak entitas terlibat dan membentuk rantai nilai untuk memenuhi kebutuhan pelanggan. Penguasaan seluruh titik dalam rantai pasok jelas merupakan solusi untuk bersaing, bahkan sebaliknya perusahaan menjadi tidak fokus, lamban, dan pada akhirnya justru tidak responsif terhadap pelanggan. Integrasi logistik pada model rantai pasok berupaya mengharmoniskan antar supply dan demand dari berbagai entitas tersebut.

\subsection{Aktivitas Logistik}

Dalam praktik, aktivitas logistik beserta operatornya memang selalu relevan dengan aktivitas pemindahan barang beserta informasi dan jasa yang menyertainya. Aktivitas tersebut dapat dikelompokkan dalam beberapa kategori sebagai berikut:

Tabel 1. Aktivitas Logistik, Pengelola, dan Pihak Terkait

\begin{tabular}{|l|l|}
\hline Aktivitas Logistik & $\begin{array}{l}\text { Pengelola Dan Pihak } \\
\text { Terkait }\end{array}$ \\
\hline Pergudangan & $\begin{array}{l}\text { Pemilik gudang, operator } \\
\text { gudang }\end{array}$ \\
\hline Angkutan udara & $\begin{array}{l}\text { Airline, EMPU, ground } \\
\text { handling service, jasa } \\
\text { bongkar muat, airport } \\
\text { operator }\end{array}$ \\
\hline Transportasi darat & $\begin{array}{l}\text { Pemilik truk, operartor truk } \\
\text { kargo, kargo B3, kargo } \\
\text { khusus, jasa bongkar muat, } \\
\text { keamanan perjalanan, sopir } \\
\text { dan awak, pool. }\end{array}$ \\
\hline Kereta api & $\begin{array}{l}\text { Operator kereta api (PT } \\
\text { KAI), EMKA, operator } \\
\text { gudang stasiun, agen } \\
\text { bongkar muat stasiun. }\end{array}$ \\
\hline
\end{tabular}

https://ejurnal.poltekpos.ac.id/index.php/logistik/index

\begin{tabular}{|l|l|}
\hline Aktivitas Logistik & $\begin{array}{l}\text { Pengelola Dan Pihak } \\
\text { Terkait }\end{array}$ \\
\hline Transportasi laut & $\begin{array}{l}\text { Shipping lines } \\
\text { (containerized, bulk, kargo } \\
\text { B3, kargo khusus), angkutan } \\
\text { antar pulau, EMKL, agen } \\
\text { bongkar muat (stevedoring } \\
\text { atau manual, pengelola } \\
\text { gudang pelabuhan, operartor } \\
\text { pelabuhan, penyedia depo } \\
\text { kontainer, pengelola } \text { dry } \\
\text { port, penyedia jasa angkutan } \\
\text { kontainer. }\end{array}$ \\
\hline Layanan multimodal \\
& $\begin{array}{l}\text { Jasa ekspres/kurir/integrator, } \\
\text { freight forwarder/ } \\
\text { konsolidator, third party } \\
\text { logistics (3PL) providers. }\end{array}$ \\
\hline $\begin{array}{l}\text { Jasa } \\
\text { penunjang/fasilitator }\end{array}$ & $\begin{array}{l}\text { Bea dan Cukai, karantina, } \\
\text { PPJK, bank, jasa suveyor. }\end{array}$ \\
\hline
\end{tabular}

Untuk Indonesia, operator lokal sebagian besar bermain di area basic logistics, sementara operator MNC mulai mengenalkan konsep 3PL (third party logistics) dan memiliki posisi bisnis yang lebih kuat.

\subsection{Logistik dan Daya Saing Nasional}

Dalam konteks daya saing nasional, kinerja logistik (Logistics Performance Index-LPI) suatu negara juga dapat dijadikan indikator daya saing negara dimaksud (Arvis, 2007). Indeks kinerja logistik Indonesia masih jauh dari menggembirakan, yakni masih berada di peringkat dibawah 40 dari 150 negara, sementara Singapura yang hanya memiliki sedikit pelabuhan laut maupun udara, menempati peringkat atas indeks kinerja logistik, sebagaimana tergambar dalam tabel berikut:

Tabel 2. Indeks Kinerja Logistik Beberapa Negara di ASEAN

\begin{tabular}{|l|r|r|r|r|}
\cline { 2 - 5 } \multicolumn{1}{c|}{} & 2012 & 2014 & 2016 & 2018 \\
\hline Indonesia & 59 & 53 & 63 & 46 \\
\hline Malaysia & 29 & 25 & 32 & 41 \\
\hline Singapura & 1 & 5 & 5 & 7 \\
\hline Vietnam & 53 & 48 & 64 & 39 \\
\hline
\end{tabular}

Sumber:http://lpi.worldbank.org/international/scorecard/radar/2 54/C/IDN/2018

India dan China juga berupaya untuk mengejar Singapura sebagai hub logistik Asia. Singapura, yang dikenal sebagai hub logistik di Asia Tenggara, telah melakukan perubahan intensif dengan perbaikan bidang teknologi dan infrastrukturnya agar bisa bersaing sebagai hub distribusi regional yang lebih efektif dan biaya yang efisien. Berbagai faktor; yang dikelompokkan dalam faktor efisiensi dan adaptabilitas operasi, lokasi, dan ketersediaan 
sumber daya manusia, yang menempatkan Singapura sebagai hub logistik Kawasan Asia Tenggara dengan daya saing global yang tinggi (Tongzon 2004). Dengan potensi yang dimiliki, Indonesia seyogyanya dapat menempati peringkat atas baik dari segi daya saing global maupun indeks kinerja logistik.

Dalam konteks regional maupun global, sektor logistik juga menjadi isu krusial pembentuk daya saing global. Selain indikator GCI dan LPI yang masih rendah, Indonesia dihadapkan pada tekanan regional baik karena tuntutan pasar maupun dalam kerangka keterikatan dalam kerja sama seperti AFTA dan APEC. Dengan adanya perjanjian-perjanjian terkait dengan pembukaan pasar yang difasilitasi WTO menyebabkan perubahan signifikan pola arus barang. Penurunan bea masuk dan pembatasan perdagangan lain mendorong pergerakan pusat-pusat industri mendekat ke arah bahan baku atau pusat logistik di kawasan regional. Pergerakan barang yang tadinya lebih banyak berupa bahan baku, kini lebih banyak dalam bentuk komponen atau barang jadi yang nilainya lebih tinggi.

Selain pergeseran karakteristik barang, jalur pengiriman barangpun diperkirakan akan mengalami perubahan mengikuti perubahan pola transportasi global. Peraturanperaturan baru bidang transportasi dan logistik juga lebih memudahkan transportasi antar negara, sehingga membuat praktisi bidang rantai suplai harus memetakan ulang jalur rantai pasok mereka dengan menghubungkan kota-kota penting di ASEAN dalam jaringan mereka. Masalah penegakan hukum, rendahnya koordinasi lintas sektor, sistem perdagangan yang kurang mendukung, kurangnya dukungan infrastruktur dan sistem, dan rendahnya kompetensi SDM dan lembaga pendidikan bidang logistik, merupakan masalah-masalah yang sampai sekarang dihadapi dan menghambat kinerja logistik nasional (Menko-Perekonomian 2008). Untuk meningkatkan kinerja sektor logistik, pemerintah telah menyusun Cetak Biru Penataan dan Pengembangan Sektor Logistik Indonesia yang berisi visi dan kebijakan logistik nasional dalam garis besar.

Logistik yang baik memberikan manfaat besar bagi suatu negara dalam era global (Arvis, 2007). Negara dengan sistem logistik yang baik akan memiliki integrasi rantai nilai global dan memberikan daya tarik untuk investor asing. Karena perdagangan dan investasi asing merupakan kunci untuk kanal penyerapan pengetahuan asing, kinerja logistik yang buruk menghambat akses teknologi dan pengetahuan baru, yang pada akhirnya menghambat pertumbuhan produktivitas nasional. Sebaliknya, meningkatnya perdagangan akan menciptakan permintaan terhadap sistem logistik yang baik, menjadi penekan reformasi dan modernisasi layanan

\section{HASIL DAN PEMBAHASAN}

\subsection{Logistik: Perspektif Indonesia}

Indonesia merupakan sebuah negara besar baik dari sisi jumlah penduduk maupun besarnya potensi ekonomi. Ini bisa dilihat dari Produk Domestik Bruto (PDB) yang pada tahun 2018 mencapai Rp14.837,4 triliun (BPS, 2019). Indikator lain besarnya potensi ekonomi bisa dilihat dari sisi ekspor, dimana pada tahun 2018 terjadi pertumbuhan 6,65 persen dibanding tahun 2017 (BPS, 2019). Namun demikian, meski memiliki potensi besar, daya saing Indonesia dalam perekonomian global belum menggembirakan. Hal ini tercermin dari urutan Indonesia dalam indeks daya saing global (Global Competitiveness Index-GCI) yang masih rendah, yakni peringkat ke- 45 dari 145 pada tahun 2018, meningkat dari peringkat ke-47 pada tahun 2017 (WEF, 2018).

Dalam konteks manajerial, logistik berkaitan dengan kegiatan perencanaan dan pengendalian arus material dan informasi terkait didalam suatu organisasi (Ghiani, 2004). Logistik juga merupakan integrasi antara informasi, transportasi, inventori, warehousing, pengelolaan material, dan pengepakan (Bowersox dan Closs, 1996). Sedangkan the Council of Supply Chain Management Professionals (CSCMP) mendefinisikan manajemen logistik sebagai bagian dari manajemen rantai pasok yang merencanakan, mengimplementasikan, dan mengendalikan arus dan penyimpanan barang, jasa, dan informasi yang terkait baik ke hilir (forward) maupun ke hulu (reverse) dari titik asal ke titik konsumsi untuk memenuhi kebutuhan pelanggan (Vitasek 2006).

Mengingat perannya yang sangat besar dalam kegiatan ekonomi secara umum, pasar industri layanan logistik tumbuh seiring dengan pertumbuhan ekonomi. Untuk skala global, biaya logistik merupakan komponen terbesar dalam perdagangan internasional (Rodrigues 2005). Untuk skala Asia Pasifik, total pasar logistik kontrak saja sebesar US\$80,96 miliar pada tahun 2017, dan diperkirakan tumbuh rata-rata 4,6 persen selama 2018-2025 (GlobeNewswire, 2019), dengan sektor kunci untuk pasar masa depan berupa manufaktur, bisnis grosir dan retail.

Pemerintah telah menyusun Cetak Biru Penataan dan Pengembangan Logistik karena memang industri logistik ini menjadi salah satu faktor penentu daya saing bangsa. Cakupan aktivitas logistik terdiri dalam 11 sektor, sebagaimana definisi oleh WTO dan dokumen ASEAN Roadmap for Logistics Integration yang juga disepakati Pemerintah Indonesia. Kesebelas sektor tersebut dikelompokkan dalam 3 TIER: TIER I berupa Core Freight Logistic Services, TIER II berupa Related Freight Logistic Services, dan TIER III berupa Non-Core Freight Logistic Services (Menko-Perekonomian, 2008). Oleh 
karena itu, lingkungan bisnis dan persaingan industri logistikpun sangat kompleks, dari mulai industri transportasi sampai teknologi informasi penopangnya. Permasalahan yang diidentifikasi dalam cetak biru tersebut antara lain:

1. Tumpang tindih peraturan dan rendahnya penegakan hukum/peraturan.

2. Rendahnya koordinasi lintas sektoral.

3. Sistem perdagangan yang kurang mendukung.

4. Kurangnya dukungan infrastruktur dan sistem:

a. Belum adanya "hub port" nasional.

b. Buruknya manajemen interkoneksi atau sistem intermodal antar infrastruktur pelabuhan, transportasi, dan pergudangan.

c. Rendahnya kapabilitas jaringan, teknologi informasi, dan pengetahuan.

d. Rendahnya kompetensi SDM dan lembaga pendidikan bidang logistik.

Pengembangan Sistem Logistik Nasional (SLN) mengacu pada visi logistik Indonesia 2025 sebagai locally integrated, globally connected, yang diarahkan pada beberapa tujuan:

1. Memperbaiki sistem distribusi domestik sehingga setiap simpul ekonomi di semua daerah bisa terhubung dan menjadikan logistik domestik Indonesia terintegrasi.

2. Mendukung ekspor dengan mempermudah aliran barang dari sentra produksi sampai ke pelabuhan dan terhubung dengan jaringan internasional.

3. Prioritas pembangunan infrastruktur berdasarkan moda transportasi dan geografi yang akan memberi dampak ekonomi terbesar secara jangka panjang.

\subsection{Pos dan Logistik di Indonesia}

Aktivitas pos pada hakekatnya memang merupakan bisnis logistik. Kolaborasi antar operator pos sesungguhnya merupakan sebuah rangkaian rantai pasok yang bisa sangat berdaya. Logistik terintegrasi juga sudah diakui dalam Konvensi UPU.

Secara legal, pemerintah sebenarnya telah memberikan ruang gerak yang sangat strategis bagi industri pos untuk menerjuni industri logistik. Ini dapat dicermati dalam Peraturan Presiden No. 7 Tahun 2005 tentang Rencana Pembangunan Jangka Menengah Nasional (RPJMN) 20042009 yang secara tegas menyatakan bahwa "untuk meningkatkan kinerja perposan nasional, termasuk peningkatan peran BUMN pos sebagai penyelenggara infrastruktur logistik nasional dan sistem pembayaran nasional. Industri pos adalah satu-satunya pelaku dalam industri logistik yang tidak bernaung di bawah Departemen Perhubungan, sementara secara alamiah aktivitas logistik sangat lekat dengan permasalahan transportasi yang pembinaannya ada di bawah departemen tersebut.

\subsection{Kebijakan Industri Pos, Kurir, dan Logistik}

Kebijakan Industri Pos Nasional tercantum dalam UndangUndang No. 38 Tahun 2009 tentang Pos (UU Pos) yang menggantikan UU Pos sebelumnya (UU No. 6 Tahun 1984). UU Pos 38/2009 merupakan politik hukum dengan tujuan mewujudkan ketertiban, kepastian, dan kemanfaatan (keadilan) bagi pelaku usaha Pos (BUMN, BUMD, Swasta, dan Koperasi, Pasal 1 angka 1 juncto Pasal 4 UU Pos 38/2009).

Politik hukum mencakup proses pembuatan dan pelaksanaan hukum yang dapat menunjukkan sifat dan ke arah mana hukum (Industri Pos) akan dibangun, dikembangkan, dan ditegakkan. Abdul Hakim Garuda Nusantara, sebagaimana dikutip Moh. Mahfud MD, berpendapat bahwa politik hukum adalah legal policy yang akan atau telah dilaksanakan.

Legal policy meliputi:

1. Pembangunan hukum yang berintikan pembuatan dan pembaruan terhadap materi-materi hukum agar dapat sesuai dengan kebutuhan.

2. Pelaksanaan ketentuan hukum yang telah ada termasuk penegasan fungsi lembaga dan pembinaan para penegak hukum.

Future oriented (ius constituendum) dari legal policy memuat enam (6) sifat, yaitu:

1. Menyempurnakan hukum positif yang berlaku (ius constitutum) karena adanya kekosongan hukum.

2. Menyehatkan cacat-cacat yuridis setelah diadakannya judicial review atas dasar asas taat asas (mengacu pada konsep struktur piramidis Hans Kelsen tentang norma derajat tinggi (superior norm) dan derajat bawah (inferior norm).

3. Sebagai rechtsvinding (penemuan hukum), untuk mengakomodasi nilai-nilai yang berkembang dalam masyarakat sekaligus dalam infrastruktur hukum, serta memperkuat nilai-nilai nasionalisme.

4. Untuk mendapat dukungan pendapat umum.

5. Merefleksikan kemajuan iptek, kultur, religi, humaniora, dan kompetisi masyarakat terbuka.

\subsection{Sistem Pos Nasional}

Pada lintasan sejarah, BUMN Pos Indonesia mengemban amanat UPU (Universal Postal Union, Perhimpunan Pos Se-Dunia). Amanat ini, dapat dikatakan sebagai "historical right" berupa hak eksklusif (reserved service, jasa yang khusus diperuntukkan) dalam penyelenggaraan layanan 
surat, kartuPos, dan warkatPos. "Monopoli Pos" ini, berlangsung sejak zaman Hindia Belanda (tahun 1863), yang juga tercantum dalam UU Pos No. 4/1959.

Reserved service, kini, memiliki impact berkaitan dengan pembiayaan USO (Universal Service Obligation) atau PSO (Public Serivice Obligation). Hingga kini, penyelenggaraan PSO Pos yang seharusnya dibiayai negara, belum didasarkan pada metode perhitungan yang dianggap "pas" oleh para stakeholder (Pasal 15-17 UU Pos No. 38/09). Digantinya UU Pos No. 4/1959 menjadi UU Pos No. 6/1984, memberi peluang bagi swasta penyelenggara pos non BUMN untuk berpartisipasi dalam penyelenggaraan jasa Pos, meski untuk jenis kiriman tertentu dengan berat tertentu (KepMen ParPostel No. KM 38/PT.102/MPPT-94).

Pemberlakuan UU Anti Monopoli No. 5/1999 lebih meleluasakan peran swasta (Perjastip). UU Anti Monopoli ditujukan agar tidak terjadi pemusatan kekuatan ekonomi pada pelaku usaha tertentu. Selain tujuan tersebut, UU Anti Monopoli mengacu pada kesepakatan komunitas (perjanjian) internasional.

Pada produk hukum yang lebih implementatif, peran swasta kembali memperoleh legitimasi melalui PerMenHub No. KM 5/05 tentang Perjastip. Permenhub tersebut menyatakan bahwa pelaku usaha jasa titipan dapat menerima, membawa, dan/atau menyampaikan paket, uang, dan suratPos jenis tertentu dalam bentuk barang cetakan, surat kabar, sekogram, bungkusan kecil dari pengirim kepada penerima dengan memungut biaya.

Peran para pelaku usaha Pos (BUMN, BUMD, Swasta (Perjastip/Asperindo), dan Koperasi) diharapkan dapat memperluas jaringan pos (interkoneksi dan kerja sama: Pasal 1 Angka 5, Pasal 11-14 UU Pos No. 38/09) sehingga dapat meningkatkan kualitas dan kuantitas layanan pos kepada konsumen, yang bermuara pada profitabilitas dan benefitas bagi stakeholder.

Dengan demikian, para pelaku usaha Pos, memikul tanggung jawab yang sama dalam penyelenggaraan pos, termasuk kewajiban untuk menyediakan layanan PSO yang menjangkau di seluruh wilayah NKRI.

Tanggung jawab bersama, dapat diwujudkan melalui pengembangan pola kerja sama yang sinergis, sehingga tercipta inovasi-inovasi metode penyelenggaraan sistem pos nasional atas dasar efisien-berkeadilan dan efektivitas biaya. Bentuk-bentuk sinergitas, antara lain, kerjasama di bidang operasional (collecting, processing, transporting, dan delivery), di bidang aplikasi teknologi (track \& trace), dan di bidang franchising.

\subsection{Logistik Pos}

Pasal 1 angka 1 UU Pos 38/2009 menyebutkan bahwa Pos merupakan layanan komunikasi tertulis dan/atau surat elektronik, layanan paket, layanan logistik, layanan transaksi keuangan, dan layanan keagenan Pos untuk kepentingan umum" yang diselenggarakan oleh "badan usaha yang berbadan hukum Indonesia.

Selanjutnya, dalam Penjelasan UU Pos 38/2009 Pasal 5 ayat 1 huruf $\mathrm{c}$ menyebutkan bahwa layanan logistik merupakan kegiatan perencanaan, penanganan, dan pengendalian terhadap pengiriman dan penyimpanan barang, termasuk informasi, jasa pengurusan, dan administrasi terkait yang dilaksanakan oleh Penyelenggara Pos (BUMN, BUMD, Swasta, Koperasi, UU Pos 38/2009 Pasal 4 ayat 1$)$.

Ketentuan dan penjelasan UU Pos 38/2009 tersebut di atas, berpijak pada praktik bisnis bahwa aktivitas bisnis layanan pos, kurir, dan logistik telah terkonvergensi secara alamiah. Kenyataan ini dipertegas dalam Central Product Classification numbers (CPC) WTO dan UPU terkait dengan peluang yang semakin terbuka bagi sinergitas produk layanan berbasis infrastruktur Pos dalam rangka terwujudnya "pos sebagai infrastruktur logistik nasional".

\subsection{Infrastruktur Logistik Nasional}

Rencana Pembangunan Jangka Menengah Nasional (RPJMN) 2004-2009 dan Rencana Pembangunan Jangka Panjang Nasional (RPJPN 2005-2025) menyatakan bahwa "Pos sebagai

infrastruktur logistik nasional" diselenggarakan dengan merujuk pada basis transportasi nasional (multi moda) yang dapat menstimulir sekaligus mengakselerasi terciptanya daya saing (ekonomi). Konvergensi dan sinergitas global antara layanan pos, kurir, dan logistik, secara gradual dan sustain, otomatis akan semakin memperluas ruang bagi penyediaan jasa layanan pos, kurir, dan logistik, yang telah terjadi selama ini. Dalam kontrak internasional, praktik-praktik semacam ini dinamakan sebagai Lex Mercatoria, yaitu kontrak yang dibuat oleh para pedagang untuk memenuhi kebutuhan praktis, termasuk dalam menentukan bentuk, nama, dan isi kontrak.

Berbagai kontrak yang lazim dalam Lex Mercatoria, erat kaitannya dengan penyediaan jasa pengangkutan barang (komoditas/dagang) melalui laut, darat, sungai (perairan/ASDP) dan udara (Huala Adolf, 2006). Analogi Lex Mercatoria berkaitan dengan konvergensi dan sinergi produk layanan pos, kurir, dan logistik, tampaknya telah dijelmakan oleh lebih dari 10 Operator Pos (Negara-negara Anggota UPU) yang telah mengadopsi dan mempraktikkan aktivitasaktivitas pos, kurir, dan logistik (International Bureau-UPU, Bern, 2006), antara lain China Post, Czech Post, Deutsche Post, Emirates Post, Hungaria Post Office, Ltd., La Poste Perancis, Malaysia Post, dan sebagainya.

Sinergitas (konvergensi) antara layanan pos, kurir, dan logistik, pada dasarnya menunjukkan karakteristik aktivitas 
yang sama tentang bagaimana proses lalu lintas kiriman (informasi, keuangan, dan barang) berlangsung, yang meliputi kegiatan-kegiatan:

1. pengumpulan (collecting)

2. pengolahan (handling)

3. pergudangan (warehousing)

4. pengangkutan (transporting)

5. pengantaran kiriman (delivering)

6. pengurusan/penyelesaian dokumen (customs clearance/kepabeanan).

Karakteristik aktivitas tersebut merupakan rangkaian kegiatan dalam lingkup supply chain management (SCM) ataupun "logistik."

\subsection{Akselerasi Transformasi Pos Logistik Nasional}

Dibutuhkan akselerasi transformasi penyelenggaraan pos nasional sebagaimana dianjurkan dalam Guide to Postal Reform and Development (Universal Postal UnionInternational Bureau Edition October 2004, juncto Konggres UPU ke-22, di Beijing, 1999 (Beijing Postal Strategy/ BPS).

Keputusan strategis BPS merekomendasikan pentingnya:

1. pelayanan pos secara universal.

2. kualitas pelayanan dalam jaringan pos internasional.

3. kemampuan ekonomi dalam ringan pos internasional.

4. pasar dan produk pos.

5. reformasi dan pengembangan pos.

6. kerjasama dan interaksi di antara para pemegang saham.

Dibandingkan dengan Washington General Action Plan (WGAP, Konggres UPU ke-20, 1989, di Washington), BPS jauh lebih maju. Sebelumnya, WGAP telah menitikberatkan pada pengetahuan tentang pasar, stategi bisnis, kualitas layanan, strategi operasional, kemandirian manajemen dan sumber daya manusia

Demikian pula dengan Seoul Postal Strategy (SPS, Konggres UPU ke-21, 1994, di Seoul), BPS tampak lebih maju, meskipun SPS telah menekankan pada kebutuhan pelanggan, strategi bisnis, kualitas pelayanan, peningkatan operasional, kemandirian manajemen, pembangunan, dan sumber daya manusia. Berbagai kemajuan yang ingin dicapai dalam Beijing Postal Strategy (BPS, 1999), telah direspon oleh pemerintah. Pada 2008, pemerintah telah meratifikasi beberapa Konvensi UPU beserta Final Protocol, Kongres UPU ke-23, di Bucharest, Rumania, 5 Oktober 2004. Ratifikasi tersebut, disahkan dalam peraturan perundang-undangan nasional, yaitu:

1. Perpres No. 39 Tahun 2008 tentang Pengesahan Universal Postal Convention beserta Final Protocol

2. Perpres No. 40 Tahun 2008 tentang Pengesahan Peraturan Umum Perhimpunan Pos Sedunia.

3. Perpres No. 41 Tahun 2008 tentang Pengesahan Postal Payment Services Agreement (Persetujuan Layanan Pembayaran Pos).

Ketiga Perpres ini berlaku sejak 19 Juni 2008.
Urgensi reformasi yang digaungkan UPU, didasarkan pada kenyataan bahwa bisnis logistik, bisnis Pos, dan bisnis kurir, membutuhkan perhatian yang lebih luas, holistik, cermat, dan arif.

\section{KESIMPULAN}

Logistik merupakan salah satu aspek yang sangat penting dan menjadi komponen utama dalam pembentukan daya saing. Logistik baik secara konsep maupun praktis mengalami evoluasi karena perkembangan lingkungan dan perilaku pelanggan. Secara konspe, logistik terintegrasi merupakan kolaborasi dari berbagai disiplin ilmu yang tidak dapat dipisahkan lagi dalam setiap wacana pembahasan logistik dan rantai pasok.

Indonesia merupakan negara yang secara geografis maupun potensi ekonomi seharusnya memiliki sistem logistik nasional yang andal sehingga dapat meningkatkan daya saing nasional. Namun demikian, dalam kenyataannya, Indonesia bahkan kalah jauh dari Singapura, negara yang tidak memiliki keunggulan komparatif sama sekali terhadap Indonesia.

Visi dan tujuan logistik Indonesia dapat terwujud apabila terdapat hukum dan regulasi yang kondusif, infrastruktur yang memadai, ketersediaan SDM profesional logistik, dukungan teknologi informasi, dan penyedia jasa logistik kelas dunia sehingga akan mendorong terwujudnya komoditas-komoditas unggulan yang akan mendongkrak daya saing bangsa.

\section{REFERENSI}

[1] Arvis, J.F. 2007. The Logistics Performance Index and Its Indicators. Washington, D.C., The World Bank.

[2] Bowersox, Donald J. dan David J. Closs. 1996. Logistical Management; The Integrated Supply Chain Process. N.Y., McGraw-Hill.

[3] BPS. 2019. Perkembangan Ekspor dan Impor Indonesia Desember 2018. Berita Resmi Statistik, No. 05/01/Th.XXII, 15 Januari 2019.

[4] BPS. 2019. Pertumbuhan Ekonomi Indonesia Triwulan IV 2018. Berita Resmi Statistik, No. 15/02/Th.XXII, 6 Februari 2019.

[5] Ghiani, G. G. 2004. Introduction to Logistics System Planning and Control. Chichester, John Wiley \& Sons.of Productivity and Performance Management. 2009; 58(3), 254-273.

[6] GlobeNewswire (2019). Asia-Pacific Contract Logistics Market 2017-2018 \& 2019-2025. www.globenewswire.com diakses 3 September 2019.

[7] Kent, John L. dan Daniel J. Flint. 1997. Perspectives on the Evolution of Logistics 
Thought. Journal of Business Logistics, Vol. 18, No. 2 , hal. 15-29.

[8] Menko-Perekonomian. (2008). Cetak Biru Penataan dan Pengembangan Sektor Logistik Indonesia. -, Menko Perekonomian RI.

[9] Mentzer, J. M. 2004. Global market segmentation for logistics services. Industrial Marketing Management, Vol. 33, hal. 15-20.

[10] Rodrigues, A. M. 2005. Estimation of Global and National Logistics Expenditure, 2002 Data Update. -, -.

[11] Sabath, R. 1998. Volatile Demand Calls for Quick Response: the integrated supply chain. International Journal of Physical Distribution and Logistics Management, Vol. 8 No. 2, hal. 698704.

[12] The World Bank. 2019. Logistics Performance Index; Country Score Card; Indonesia 2019.

[13] Tongzon, J. 2004. Determinant of Competitiveness in Logistics: Implications for Region. International Conference on Competitiveness: Challenges and Opportunities for Asian Countries. Bangkok, Thailand's National Competitiveness Committee, hal. 1-16.

[14] Vitasek, K. 2006. Supply Chain and Logistics Terms and Glossary, Web Publication. -, www.scvision.com.

[15] World Economic Forum (2018). The Global Competitiveness Report 2018. Undang-Undang Nomor 38 Tahun 2009 Tentang Pos.

\section{Peraturan Perundang-undangan}

[1] Undang-Undang No. 17 Tahun 2007 tentang Rencana Pembangunan Jangka Panjang Nasional (RPJPN) Tahun 2005-2025.
[2] Undang-undang Nomor 10 Tahun 1995 Tentang Kepabeanan.

[3] Undang-undang Nomor 5 Tahun 1999 Tentang Larangan Praktik Monopoli dan Persaingan Usaha Tidak Sehat.

[4] Undang-Undang Nomor 6 Tahun 1984 Tentang Pos.

[5] Peraturan Presiden No. 7 Tahun 2005 tentang Rencana Pembangunan Jangka Menengah Nasional (RPJMN) Tahun 2004-2009.

[6] Peraturan Menteri Perhubungan Nomor: KM 5 Tahun 2005 Tentang Penyelenggaraan Jasa Titipan.

[7] Keputusan Menteri Pariwisata, Pos, dan Telekomunikasi Nomor. KM 38/PT.102/ MPPT-94 Tentang Perusahaan Jasa Titipan.

\section{Jurnal dan Makalah}

[1] Abdul Hakim Garuda Nusantara, "Politik Hukum Nasional", makalah pada Kerja Latihan Bantuan Hukum, LBH: Surabaya, September 1985.

[2] Sutan Remy Sjahdeini, "Latar Belakang, Sejarah, Dan Tujuan UU Larangan Monopoli," Jurnal Hukum Bisnis, Volume 19, Mei-Juni 2002.

\section{Dokumen Lainnya}

[1] UPU (2008). Acts of the 24th Congress - 2008. Universal Postal Convention and Final Protocol (pp. 1-42). Geneva, the UPU.

[2] UPU. (2004). Guide to Postal Reform and Development. Bern, the UPU-International Bureau. 